\title{
Social Constructionism and the Corporate Brand: Semiotic Analyses of Print Adverts
}

\author{
Oluwaseun Akindele \\ School of Media \& Communication, Pan-African University, Victoria Island, Lagos, \\ Nigeria
}

Jeremiah Iyamabo

Lagos Business School, Pan-African University, Ajah, Lagos, Nigeria

Tel: 234-810-323-5988Ｅ-mail: jiyamabo@lbs.edu.ng

Olutayo Otubanjo

Lagos Business School, Pan-African University, Ajah, Lagos, Nigeria

Received: April 19, 2013 Accepted: May 15, 2013 Published: June 24, 2013

doi:10.5296/bms.v4i1.3547 URL: http://dx.doi.org/10.5296/bms.v4i1.3547

\begin{abstract}
Over the years, brand-building arguments have focused on process models; that is, brand-building and formation processes developed from historical and cultural foundations of the brand visionaries. They are then translated to the vision statements of corporate brands and the internalization of brand values in those who represent it. However, the question of meaning in the brand building process is often left out in the models spread across the extant literature. The authors, therefore, adopt a social constructionist approach as the theoretical basis for building the corporate brand. This attempt culminated in a proposed model embedding in social constructionist tenets and applied to corporate branding. In an attempt to validate the theoretical arguments, the authors carried out field interviews with brand custodians of two Nigerian banks. Semiotic analyses of samples of the banks' print advertisements were also carried out to understand how the banks' construction of meaning informs their brand building process. The findings revealed consistencies between the origin and socio-cultural derivations of meanings and brand communication as an important brand-building component. Recommendations on how this process can be adopted and
\end{abstract}


operationalized in industry were therefore made.

Keywords: Social constructionism, Semiotic analysis, Brand meaning, Brand myth, Corporate branding 


\section{Introduction}

Scholars have made several attempts to examine the subject of corporate branding with the view of presenting a more coherent understanding of the brand building process (e.g. Stephen, 1991; de Chernatony \& Harris, 2000; Harris \& de Chernatony, 2001; Karreman \& Rylander, 2008). This has led to the development of brand management and brand building models. Some of the most notable contributions found in the branding literature are contained in the following works: de Chernatony \& Dall'Olmo Riley (1998), Keller (2001), de Chernatony \& Segal-Horn (2001), Rust, Zeithaml \& Lemon (2004), and Burmann \& Zeplin (2005). The conceptualizations, which develop therefrom, are based on studies - field interviews of brand custodians - as well as observations of approaches and strategies used by successful brands in industry. These conceptualizations have made significant contributions in terms of explaining the brand building process from various perspectives. However, the question of how reliable this dominant process is as the bedrock of brand-building and development, continues to elude the branding literature.

de Chernatony \& Dall'Olmo Riley (1998a); for instance, present a double-vortex model which is representative of the decision steps of management for an effective and efficient brand building process. These steps incorporate "vision", "mission", "values", "culture", and "heritage". The model also presents an interface between input and output functions of the brand (see also, de Chernatony \& Dall'Olmo Riley, 1998b) expected to be well garnered by brand custodians. However, the question of which underlying principle will guide brand custodians in operationalizing the brand building process remains elusive in de Chernatony \& Dall'Olmo Riley's (1998) proposition. Similarly, Keller (2001), tends to focus on building the brand based on the equity generated by its customers by presenting the CBBE model; a relationship building model aimed at unearthing the vast, collective stock generated through customer perceptions. Essentially, Keller's position presents an alternative to earlier authors (i.e. a customer-centric brand development model) rather than a deeper proposition as to the social theory origins of the CBBE model.

As it is typical of trends in academic debates, other authors continued in the same direction by focusing on how best to operationalize brand-building models. For instance, reactions have tried to establish the difference between brand management and brand equity (see Rust, Zeithaml \& Lemon, 2004). Burmann \& Zeplin (2005) on the other hand use an identity based management approach, which begins at the internal environment (employees in the workplace) to form entrenched behaviours representative of the values of the brand. The position seems to be consonant with the findings of de Chernatony \& Segal-Horn (2001) who extend the argument of internalized processes to emphasize relationship building between the internal brand process and external stakeholders. In the light of this background, and notwithstanding all of the efforts and contributions made in the brand process models, the authors propose a brand building approach hinged on social constructionism. Indeed, we find that in profoundly un-articulated ways, some of the brand process models can be better understood from a social constructionist point of view. In deploying this approach to understanding the brand, the authors first make an attempt to articulate how this approach can be used for brand building within the organization. Following this, an investigation of the 
construction of meaning was carried out using semiotic analyses of brand communication (print) advert copies.

\section{Literature Review}

Berger \& Luckmann (1966) became the first highly influential position on social constructionism as an epistemological approach to understanding man's construction of reality. Social constructionists see objects of thought as emanating from deep beliefs in society. Society itself operates as a continuous cyclic of social interactions - which by itself, cannot occur as a continuous cyclic without shared beliefs between the communicative agents. Therefore, by extension, objects of thought emanate from shared and common interactions between the communicative agents (Shotter, 1993). As common ideas and beliefs continue to emanate from social interaction, they become reinforced not just as reality but as "objective" reality. This is operated through a shared aphorism that if a common set of thoughts and beliefs continue to resonate among groups and individuals based on interactions and shared meanings, such thoughts and beliefs must represent their conception of reality; in essence, a consistent part of their worldview. As a result, objectivity emanates from what is otherwise regarded as a subjective process of social construction, intrinsic to a given circle - of individuals, groups, caucuses, a particular society, or even a civilization.

In this process of developing a common conception of reality from shared and negotiated meanings, the actors, interacting together in a social system, over time, develop concepts or mental representations of each other's thoughts, actions and nuances. These concepts eventually become habituated into reciprocal roles played by the actors in relation to one another. When these roles are made available to other members of society to enter into, play out, and reciprocate, the reciprocal interactions are said to be institutionalized. In the process of institutionalization, meanings are embedded in society. Knowledge and people's conception and belief of what reality is, is then embedded in the institutional fabric of society. Hence, social reality is therefore said to be socially constructed. Berger \& Luckmann (1966) propose four important components constituting social constructionism consisting of: collaboration, habitualization, objectivation and institutionalization. The authors therefore, deploy these tenets as the basis for understanding how managers construct and define (meaning) the identities of their brands through a constructivist and socio-cultural perspective by developing a social constructivist corporate brand development model (see Figure 1). Essentially, Figure 1 below is an attempt to embed Berger \& Luckmann's propositions within the context of a corporate organization - which must define, ascertain and communicate its identity to the larger societal space. 


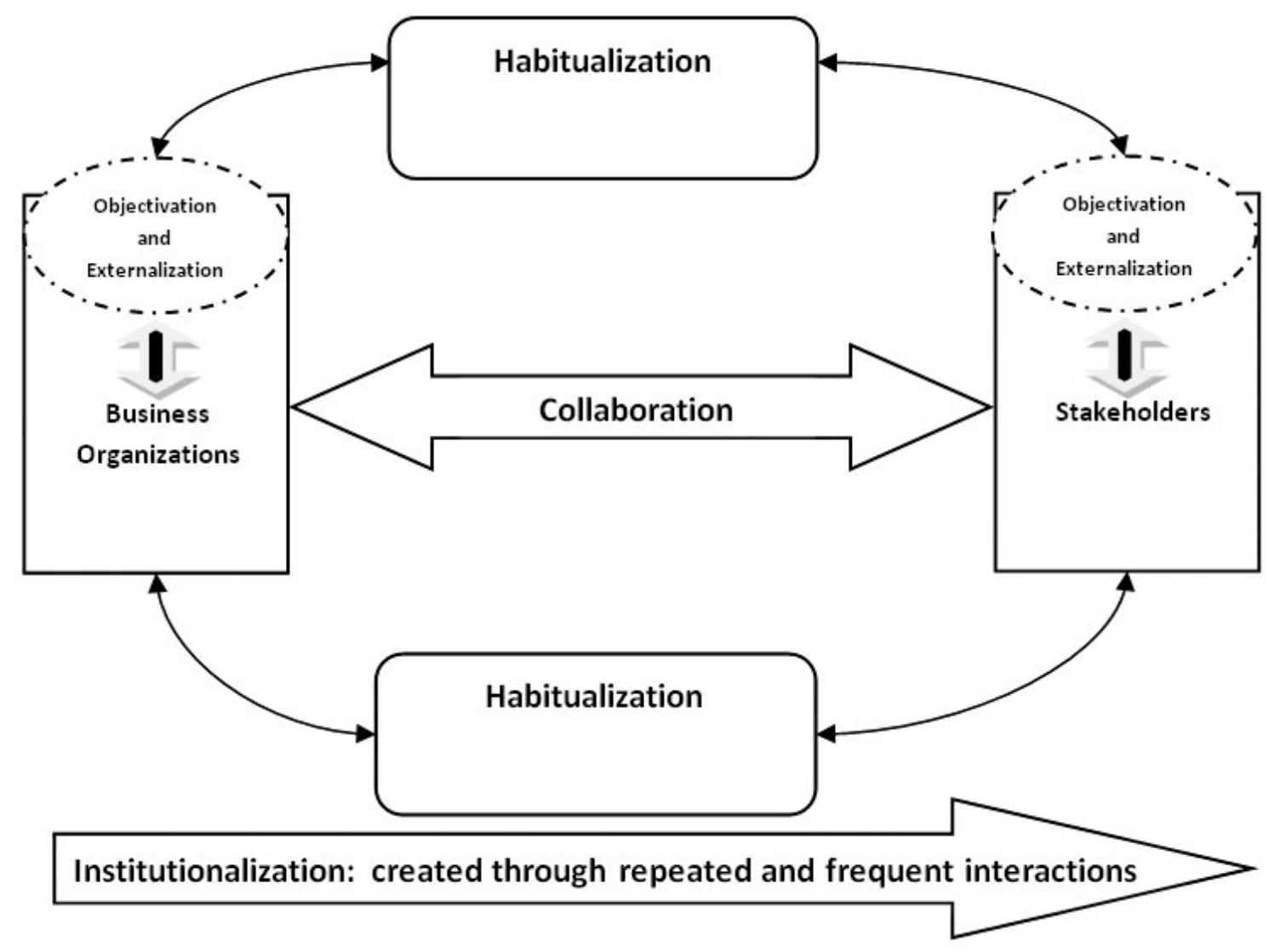

Figure 1. A Social Constructionist Corporate Brand Development model

For the purpose of clarification, the four tenets of Berger \& Luckmann's (1966) theory, applied within the context of the corporate brand, are enumerated in the following paragraphs.

Collaboration: Berger \& Luckmann (1966) propose that man, a product of necessity, is a social enterprise, implying that man alone cannot produce the environment and indeed an enterprise, hence the need for socialization. Similarly, business organizations cannot operate in isolation within an environment. They must interact as a going concern with stakeholders such as customers, media, government, suppliers, host communities, employees, investors, financial institutions etc.

Habitualization: when an activity is carried out frequently, and over a period, it becomes cast into a pattern. Consequently, minimal economic effort will be applied in the future to carry out the same task. This is what Berger \& Luckmann (1966) refer to as habitualization. Their sociological theory is likewise applicable in the field of corporate branding. Business organizations carry out certain functions repeatedly; becoming a behavioural pattern. An example in this regard is the (re)production of corporate advertisements by the corporate communications department of many corporate brands. When business organizations produce corporate advertisements, time after time, they retain and use certain components of their advertisements which may be called "templates" repeatedly. Under such conditions, the use of such components becomes cast into a pattern leading to habitualization. The 
implication of these templates for such organizations is that, subsequently, minimal economic effort will be required to produce future advertisements when they are needed.

Objectivation and externalization: Berger \& Luckmann (1966) argue that man accepts the objective world that he has meets without questioning it because it has been passed down to him from his ancestors. In other words, the objective worlds we live in are consequences of an institutionalization process or institutions created when they are passed from one generation to another. Consequently, the following generation inherits it and takes it as something given; self-evident and unalterable, without necessarily understanding the attending logic. In short, these institutions become an undeniable fact regardless of whether or not new members of society understand it. Ultimately, they contribute to the shared meanings among members of society. The principle of "objectivation" and "externalization" also applies to business organizations given that in the brand-building process, they cultivate certain cultures, norms, nuances etc, which become a way of life for people within the organization. These nuances are further passed down to generations of later employees who work in the same organizations in the form of "mission statements", "vision statements", "policy documents", strategic documents, etc, - all geared towards ensuring a common corporate culture; therefore, becoming objective realities for them. This process of objectivation ensures that there is a transition of corporate culture in the life of an rganization from one generation of workforce to another and it helps to ensure that the organization's life can extend beyond the existence of its founders and promoters.

Institutionalization: this occurs whenever there is a reciprocal typification of habituated actions by types of actors. The authors contend that the reciprocal typification (a thing given or done in return for something else) helps to build institutions. Similarly, in the business environment, organizations also operate through typification of habituated actions. This often involves organizations on the one hand and stakeholders on the other. In the process of interacting repeatedly with one another, a relationship is built leading to habitualized actions. Such habituated patterns and processes lead to institutionalization of the interaction. It is on this basis that the relationships in societies can be said to be institutionalized. In addition, in today's business environments, notions of institutionalization occur when business organizations interact repeatedly and frequently over time with stakeholders. These sustained interactions build the relations between business organizations and stakeholders leading to institutionalization. Arguably, the process of branding is situated in the institutionalization process, which is also a signification of interactions and relationships.

\section{Methodology}

Although interest in signs and the way and method they have communicated meanings have come through history from the time of John Locke and other philosophers, semiotic analysis in its modern form can be traced to two individuals: Swiss linguist, Ferdinand de Saussure (1857-1913) and American philosopher, Charles Sanders Peirce (1839-1914). While there are differences in their opinions, the correlation between these works is concerned with signs. According to Saussure (1915/1966), 
the linguistic sign unites not a thing and a name, but a concept and sound-image. His work divided signs into two components, the signifier (sound-image) and the signified (concept), and he suggests that the relationship between the signifier and the signified is arbitrary, and were crucial and important for the development of semiotics. Pierce on the other hand argues that interpreters have to provide part of the meanings of signs and that "a sign is something which stands to somebody for something in some respect or capacity" as quoted in Zeman (1977, p. 24). As an interpretive approach to research, semiotic analysis provides a qualitative method used in studying images and body copies of a given work. It is the most preferred means of deconstructing advertisements and corporate identity materials for its ability to bring to the fore, entrenched meanings.

Another notable contributor to the epistemology of semiotics is Roland Barthes. He examined and commented on the activities of the French bourgeois through the critiques of the cultural materials of the bourgeois' imposition of its values on others. He used semiotic analysis to explain these materials using now established languages of semiotics like cultural myths, connotations, denotation, signifier, signified etc, and how subjective these results were on the locals - making his work a reference point in the analysis of signs as carriers of meanings using semiotic methods. Therefore, following the method as laid down by Barthes, which this work will adopt; there are three main processes in carrying out a semiotic analysis namely: making a denotation of the text, then followed by making a connotation and lastly, a mythical link of the textual content. For the purpose of this research, denotative analyses will attempt to provide descriptions of the texts being analyzed by taking into consideration the body-copy of the texts. The purpose is to reveal the actual meanings of the texts rather than what they imply. Copies of the analyzed texts (Figures 2 and 3) are therefore included for purposes of illustration and clarification. Connotative analyses, on the other hand, will attempt to provide solutions to implied meanings of signs or texts under consideration. Semiotic connotative analysis usually provides insights into why certain messages are crafted in certain ways. At this point, the texts being analyzed by the researcher are from the perspective of either the "signifier" or the "signified".

For the purpose of analyses two Nigerian banks were chosen from the existing commercial banks available in Nigeria $(n=25)$ at the time of conducting this research: First Bank of Nigeria plc (First Bank) and Skye Bank plc (Skye Bank). The choice of these organizations was made using judgmental sampling. First Bank was chosen on the basis of having the longest history (i.e. 111 years, by the year, 2005) in the Nigerian financial services sector. The bank also prides itself as being the first Nigerian bank as it strives to continuously relay this message in its brand communication materials. Skye bank was chosen based on its success as one out of six new banks (as of December, 2005) birthed by the merger and acquisition process which redefined the Nigerian banking sector in the year 2005 (Note 1). Finally, the purposive decision of the researchers was further informed by the active participation by both banks across the Nigerian mainstream media. As a result, the researchers perceived both banks as a balanced representation of the Nigerian banking sector given their aggressiveness in the areas of brand building and brand communication efforts especially in the areas of "meaning construction and derivation", and "corporate 
brand identity". Finally interviews were conducted with marketing and corporate communication executives of the respective brands with the view of gaining insight on the interpretation of the various elements of the banks' advert copies (Figures 2, 3) from the constructionists' point of view. The purpose was to cross-reference the intended (constructed) meaning with the subjective meaning of the advert copies as a way of validating the result of the semiotic analysis.

\section{Semiotic Analyses \& Interpretation}

\subsection{Skye Bank plc: Semiotic analysis of corporate print advertisement}

Denotation: The text is a full-page newspaper advert of Skye Bank plc placed on page 35 of THE PUNCH newspaper of December 28, 2008 (see Figure 2 below). The copy is created on a lemon page with light and dark blue colour used for the letterings. The body-copy contains an image of a yawning man, putting on a red t-shirt, with a yellow pillow behind him and a blue cover cloth on his laps. The copy starts with the letter " $H$ " in deep blue colour (each leg of " $\mathrm{H}$ " has a thin vertical strip of yellow), having a larger and different font and size from the other letters. The copy reads "He who puts his money under the mattress ends up sleeping on the floor" with a rider; a quote by the former MD/CEO of the bank, Akinsola Akinfemiwa which reads:

In uncertain times, the ostrich buries its head in the sand just like those who keep their money under the mattress. Such intuitive responses to difficulty can only make things harder. Instead, it's important to seek out a faithful companion who can act as a guide through hard times and ensure a soft landing, so you won't be caught napping when you should be planning for tomorrow.

The copy also has the words: "can you save today to secure tomorrow? Yes! You can". The "yes" is in larger font size, light blue letters and has arcs underneath it. At the base of the copy is a thin horizontal strip in deep blue, and on it is a large logo of the bank. The logo is a lemon yellow coloured circle stripped in deep blue colours that contains the letters of the name "Skye Bank" with three arcs: white, light blue and deep blue placed over the words. The copy ends with the bank's website address: <www.skyebankng.com> under deep blue strip. At the beginning of the copy is a small horizontal strip in deep blue that contains the words: "four days to go" in white colours.

Connotations: the "he who puts his money under the mattress ends up sleeping on the floor" which is to add to the meaning of the copy's image of the yawning man, whose yawning, coupled with the pillow and the cover cloth indicates that the character in the copy emphasizes that not putting one's money in the bank but keeping it under the mattress can prove problematic for such persons; just like the case of an ostrich with its head in the sand leaving the larger part of its body vulnerable. The yawning man with his red t-shirt indicates that it will be dangerous for someone not to put his money in the bank, the red t-shirt indicates the danger inherent in it, and the yawning indicates that the man will have sleepless nights because of watching over his money. This scenario shows that there is no peace of mind for anyone who does not keep his money in the bank. The quote from the former bank 


\section{Macrothink}

managing director emphases the fact that people need a reliable companion in troubled times, (i.e. Sky Bank plc), that will provide a platform; a companion, for those who are preparing for tomorrow. Also, the rider beneath it "can you save today to secure tomorrow? Yes! You can" emphases the fact that people can save for the future and they can do that with Skye Bank plc; to show that the bank is a credible bank that customers can rely on. The "yes!" connotes that the bank is interested in saying "yes" to the concerns and possibilities of its stakeholders - as a faithful companion that can act as a guide through hard times. The logo of the bank is placed at the right side base of the copy consisting of the colours: white, sky-blue, lemon yellow, and deep blue. The lemon yellow colour is an indication of gaiety or friendliness, meaning that the bank is friendly; the sky blue colour indicates tranquility and peace of mind; the white colour indicates that the bank has clarity of purpose laced with convictions; and the deep blue shows a seriousness that is required for handling people's money. As such, the bank's website is placed at the bottom left of the copy.

Myth/Meaning: The use of a young clean-shaven yawning man putting on a red cloth, and who is still sleepy invokes in the mind of readers the idea of a hard working person that has made some money for himself, but who has no rest of mind due to the fact that he is afraid to keep his eyes closed for the fear of losing his money. From the text, it shows that Skye Bank plc provides peace of mind, dedication, tranquility and has a friendly disposition towards its stakeholders. And in its discourse with its stakeholders, it says that it is a "yes" bank; saying "yes" to the needs and aspirations of its stakeholders. In other words, its construction of its reality is that the bank is a safe place for customers and investors to rely on; a social myth in the context of social discourse. 


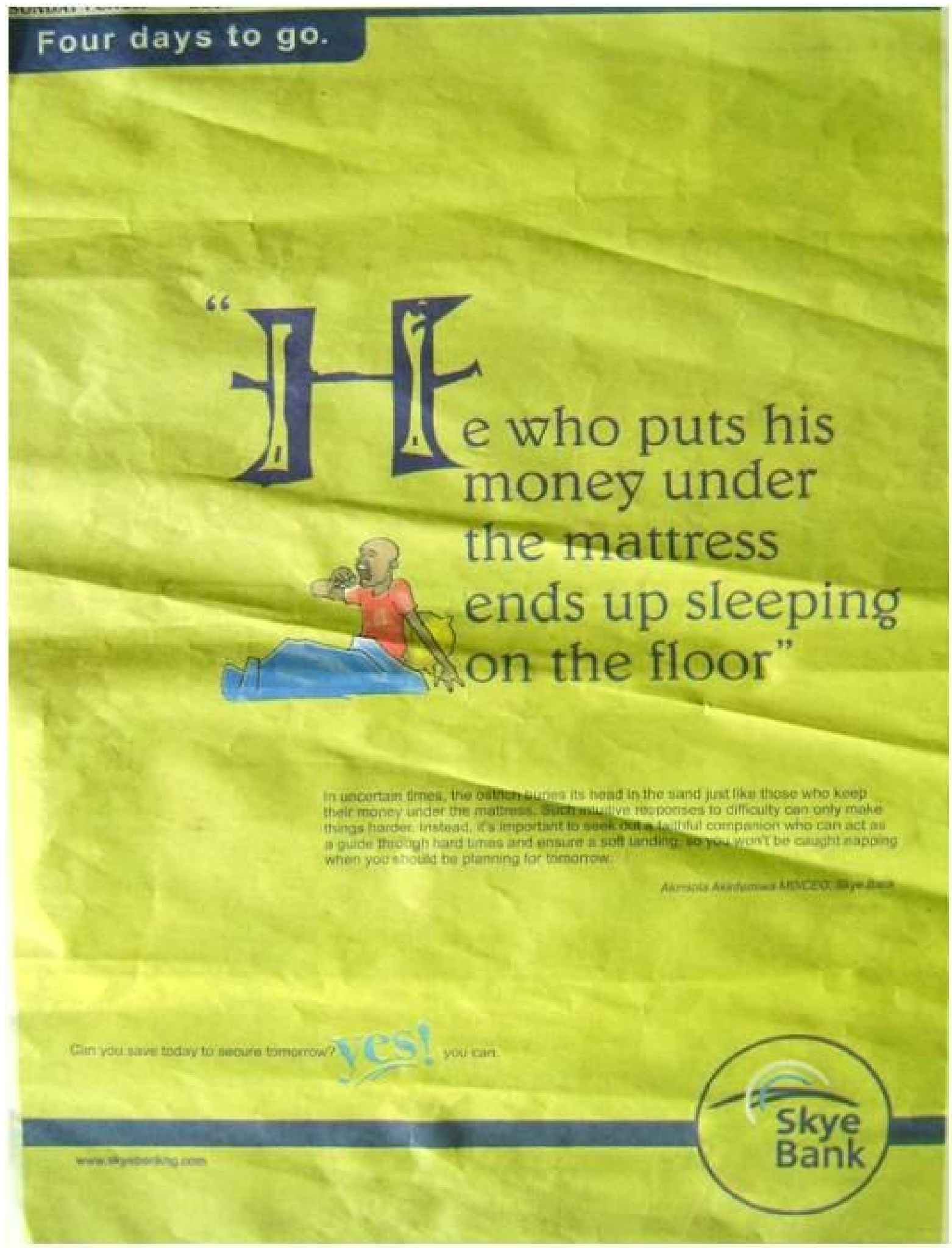

Figure 2. Skye Bank plc print advert published in THE PUNCH newspaper (December 28th, 2008, p. 35) 
4.2 First Bank of Nigeria plc: Semiotic analysis of corporate print advertisement

Denotation: This text is a full-page press corporate advertising material placed in THE GUARDIAN newspaper of Friday, October 15, 2010 (see Figure 3). This copy is made in a mix of the brand's colours: deep blue, light blue and a splash of white titled, "pardon us for blowing our trumpet". The font size is set at about 36 point and written in deep blue. The copy is divided into two halves; both in different shades of blue. The right side of the copy contains the bank's logo which is a nimble elephant inscribed in a square shaped box with a blue background. At the bottom of the nimble elephant is the bank's name "First Bank" and the expression: "since 1894" on the white shade of the logo. Beneath the logo is the expression: "first for information security" and under that is a plaque (in brown wooden colour) which has written on it, amongst other things, "certificate of registration". Under this expression is another expression as follows: "proof that we are truly the first". Lastly at the base of the copy is the classic payoff of the bank in white and yellow colours "First Bank...truly the first". On the left side of the copy written in deep blue colours are the following words:

Pardon us for blowing our trumpet

We are the first organization in Nigeria to achieve the information security management system ISO/IEC27001; 2005 Certification. This means our customers have more reasons to rely on us for dependable financial services: World class security standards; System interoperability; Quality assurance; Due diligence; Confidentiality and integrity of information assets".

Under these are listed the countries/cities where First Bank can be found: Nigeria, London, Paris, Johannesburg, and Beijing. Underneath that is written: "for all enquiries call: FirstContact-0700FIRSTCONTACT 700-34778-2668228); 01-4485500; 0708-062-5000). Email: firstcontact@firstbanknigeria.com; www.firstbanknigeria.com RC:6290 


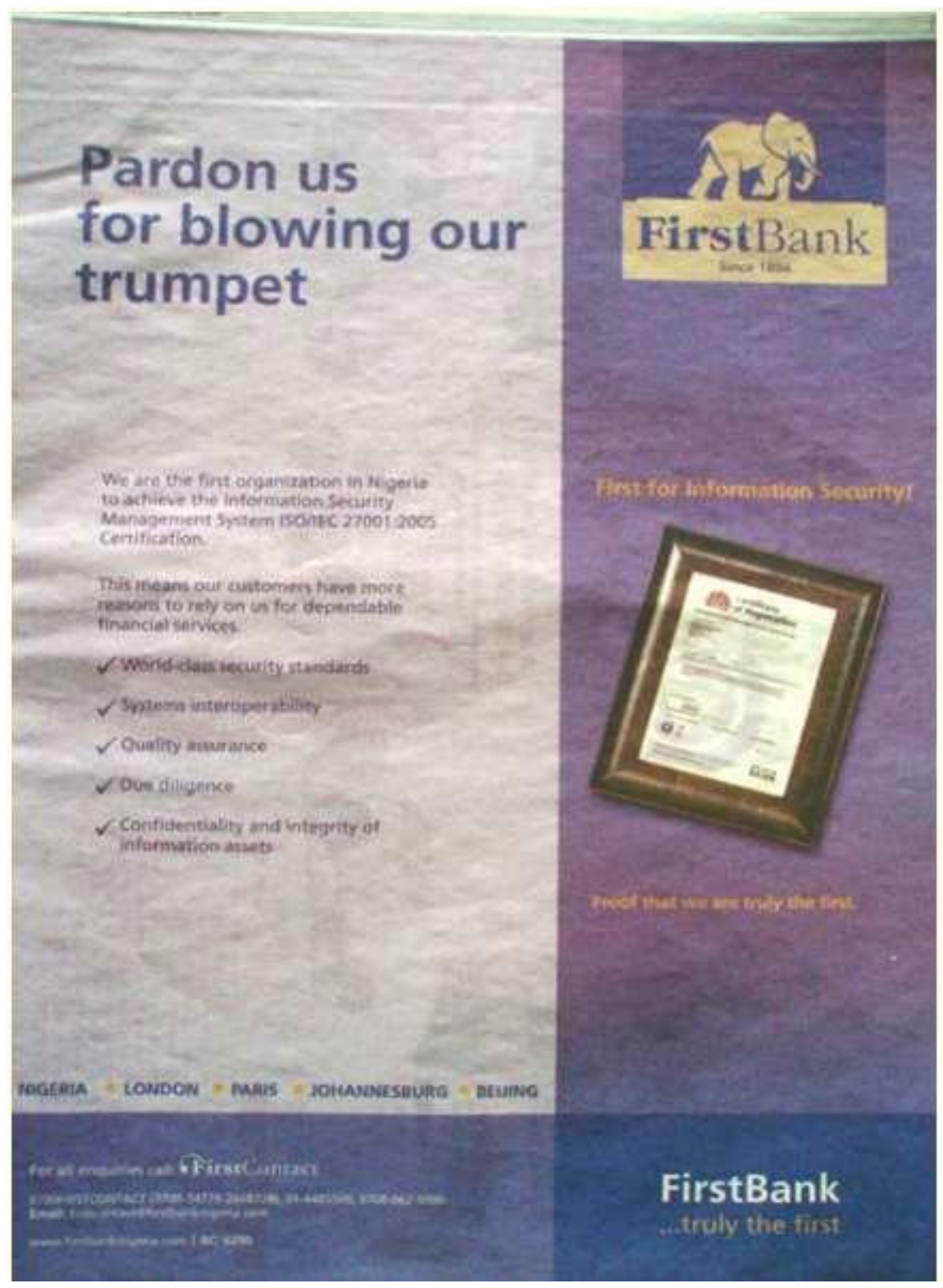

Figure 3. First Bank of Nigeria plc print advert published in THE GUARDIAN newspaper (October 15th, 2010)

Connotation: The body copy "pardon us for blowing our trumpet" connotes the feeling of pride and achievement of what the bank has done; the legacy of the consistencies and innovations they have been able to deliver over the past years as the first bank in Nigeria. It is further strengthened by the description of the achievement "we are the first organization in Nigeria to achieve the information security management system..." All these reinforce the claims of the corporate logo. The expression, "since 1894" and the image of the nimble elephant signifies that the bank has the capacity and strength of an elephant and can similarly be swift, powerful and responsive, making it a choice place of safety for banking and investment decisions. This is so because it provides safe, fast and secured banking transaction. The other part of the copy on the left expands on the bank's capacity, which also includes the fact of being ready to make use of opportunities within its 
environment. This buttresses the fact that it is the first bank established in Nigeria and takes the lead in been innovative and dynamic, this it has done with the acquisition of the information security management system ISO/IEC27001; 2005 Certification, and the first bank to do so in Nigeria; further strengthening its claims as a reliable and dependable bank. The claims include having world class security standards, system interoperability, quality assurance, due diligence, confidentiality and integrity of information assets, which are also to reinforce the bank capability, strength, reliability and dependability at all times. The claim is also strengthened by the picture of the plaque in the text to show the validity of these claims. The mention of the countries/cities in which the bank operates is to emphasize the bank's size and volume of assets. The bank's payoff and its name at the bottom right of the copy drives home the fact that the bank is truly the first in Nigeria. The contact details, which include its website, email address and telephone numbers, give a sense that the bank is a caring brand and is willing to provide an interactive, tailor-made, world-class financial service to their customers and other stakeholders.

Myth/Meaning: The strategic placement of the bank's logo with the headline offers a meaning and a myth: we are the first, the biggest; we do big things and we are not afraid to blow our own trumpet". The blend of the shades of blue from an ocean blue colour to a deep blue creates an experience of being youthful, fresh and wise, a demeanour that comes with age and experience. The wisdom and capacity which the bank describes can only come with being in business for over a century; making a call that the bank has a history of competence. Positioned as the largest bank in Nigeria from the uniqueness of the African elephant as the strongest and largest land animal resonates the power, strength and efficiency that corporate and individual customers of the bank need from their financial institution. The myth which relates all of these together is the fact that being the first bank in Nigeria, they have, through the years been, able to renew themselves and set the pattern of consistency and world-class performance in the industry, making them the trendsetter in the financial services industry in Nigeria. In other words, any one that banks with First Bank can be assured that their money is safe.

\section{Discussion}

\subsection{The Corporate Brand: Myths and Meanings}

The myths/meanings conceived from all of the examined brand communication messages indicate that the banks' construction of their realities have been done from three identified perspectives. The first is from the need to ensure that there is an effective dialogue between the institution and its stakeholders. Secondly, there is emphasis on the habituated pattern of behaviour that the institutions have been able to practice so well and are proud to offer their stakeholders with minimal economic effort. These habituated patterns and cast are seen in the logos, colours used, payoffs, locations and contact addresses, website addresses, telephone numbers etc. Thirdly, the banks have been identified as going through the process of institutionalization which is required to formalize a brand. In other words, the process, myth and meaning identified from the semiotic analysis indicates the process of brand building. In the case of First Bank, for instance, the emphases on the fact that they are the first bank to be 
established in Nigeria (since 1894), shows that the process of institutionalization advocated in this work can be found in the structure of First Bank. The same applies to Skye bank; the process of institutionalization can be highlighted in the number of years of their existence, the change in leadership structure, and the movement of staff in and out of the bank over the years. The process of institutionalization as advocated in this work also looks out for the offerings of the brand in the discussion of the social construction of their realities. The emphasis is drawn here that these brands are corporate brands and therefore, their offerings have to be value based. Therefore, the value propositions of First Bank as being "truly the first" might connote different meanings to their different clients. The expression Skye Bank uses which says they are a "yes" bank, might also connote different meanings to their different stakeholders - for as long as meanings continue to shift from individuals to individuals and from one group to another.

\subsection{Interpretive Interview Analysis: Skye Bank plc}

An interview was conducted with one of Skye Bank's brand management executives at the bank's head office in Victoria Island, Lagos. Responses to the field questions revealed the following:

Mandatory elements which must be included in the bank's advert materials include: a) Company bar - this comes with the corporate logo made up of strips in the bank's colours of horizon blue, future green, and the sky blue. Also, the "yes" comes in as the typical brand language. These colours: sky blue, horizon blue, and the future green, are to depict what Skye Bank represents. The horizon blue, which is deep blue, depicts the conservativeness of the bank. The sky blue, which is the lighter blue, shows the possibilities that the sky offers; its limitless scope and space, providing the language and payoff of the bank as a bank that is "expanding your world", while the future green gives an insight into what Skye Bank is into (i.e. "the being") to expand businesses into the future. This idea of the future green is a coinage of a "green future, a green tomorrow". The bank's stakeholders include the banking public, customers, shareholders, government agencies, staff, etc, and the kind of image that they are trying to project to them is that they have a partner that they can walk with to achieve their dreams.

The second mandatory element is b) the bank's logo: the arc looking swooshes actually depict the sky, which is about Skye Bank's ability to present possibilities that are ever expanding to their stakeholders. In all the bank's messages, the bank tries to encourage saving for the future. These messages have indeed built the bank's brand over the years. The value propositions are to provide limitless possibilities to everybody; they want to make lifestyle easier for their customers, provide benefits to all stakeholders. The "yes" statement also offers a can do spirit, and to acknowledge the possibilities in human processes.

While it is acknowledged that some elements appear different from the interpretation of the banks' process, analysis done by the researchers and the interpretive interviews done with the brand managers, it is adequate to say that the interviews have been able to support the claims of this research on how brands are constructed by brand owners. 


\subsection{Interpretive Interview Analysis: First Bank of Nigeria plc}

Interviews were conducted with marketing and corporate communications executives at the bank's head office located at Lagos Island, Lagos. The executives' responses to field questions revealed the following:

The bank considers certain elements as mandatorily included in their advert materials. These include: a) "tone of voice" which must be professional but not arrogant, emphatic and confident throughout its message; $b$ ) the bank colours which are: blue and tan. Blue was chosen because the bank associates itself with royalty, which is transposes to their cool and sophisticated disposition. The ivory colour, "tan" is adapted from the representation of the elephant as the logo of the bank; c) typeface - only approved font types are used to create the bank's advert copies in order to ensure consistency in its communication material which extends to the firm's corporate identity

Secondly, the bank ensures that its communication (advert copies) speak to its stakeholders directly which the bank categorizes as: a) typical customers - by designing its communication to convey the caring, safe, and sturdy disposition of the bank; b) industry regulators - such as the $\mathrm{CBN}$ and NDIC (Note 2) - whom they try to address from the perspective of due diligence; c) Industry peers (or competitors) - to whom they need to constantly affirm their superiority as pacesetters in the industry; $d$ ) Investors and financial analysts - whom the bank sees as important stakeholders to them due to their influence as existing and potential business owners and advisers, and as a result, potential investors in the business. The bank communicates the fact that it is a bank with excellent corporate governance. All these communication strands ensure that the bank grows into a strong brand.

In addition to the above, the respondents mentioned that there are other key value propositions which the bank tries to communicate which are: dependability, trustworthiness and leadership. Again, these qualities are tied to the symbolic elements such as the firm's logo - the elephant. The elephant's attributes that are synonymous with First Bank given that it is the largest land animal; it is big, strong and long lasting thereby an appropriate reflection of the bank's market share and position in Nigeria's financial services industry. It also signifies strength just as the bank has consistently demonstrated its leadership position with lasting power and longevity. As a result, all of the firm's activities, including its communication materials must relay these attributes of the elephant through its demonstration of strength, solidity, dependability and longevity. Encapsulating all of the above is the bank's value propositions which are: trust, dependability and resilience. These values ensure that the bank speaks to all its stakeholders through their marketing communications messages and this has influenced their brand building efforts.

\section{Summary, Conclusion and Recommendations}

The discussion commenced with the premise that brand-building efforts by brand owners and/or managers operate through a process of social construction of the meanings of respective brands, which leads to identity formation. This determination required a review of the social constructionist literature, which revealed that many of the scholarly works in the 
brand building literature focus on positivist methodology as a pivot for understanding the corporate brand. In addition, the existing attempts of social constructionism presents an alternative school of thought for understanding the corporate brand. In addition, few existing research efforts, which make arguments for social constructionism vis-à-vis corporate branding, contain findings drawn from societal and cultural contexts which are not necessarily suited to the Nigerian socio-cultural context thereby amounting to significant semantic gaps in the process of interpretation. As a result, their conclusions cannot be extended to be all encompassing.

The gaps identified above led to the formulation of a research question, which this paper attempts to address conceptually and empirically. Conceptually, a theory for social construction of brands was postulated, and an attempt was made in Section 2 to provide justification to the conceptual model provided with the social constructionist view. Sections 4 - 5 contain empirical findings based on analyses of (print) advert copies and field interviews of senior executives of two corporate brands in Nigeria's financial services industry. Based on the above findings, the following four-stage process enumerated in subsequent paragraphs as findings addresses the central concern of this research.

\section{First finding: Habituated pattern of visual identity management process}

Organizations must have a series of activities and processes which they carry out repeatedly, over a period of time and which become cast into a pattern; consequently requiring minimal economic effort to be applied in future to carry out the said set of activities. What this implies for the brand is that they is that they must look at entrenching processes, patterns and models that they adopt as part of their brand's mandate. Such a set of activities and/or processes must cohere and be consonant with the brand's philosophy, mission statement, vision statement, logo, colours, etc, which becomes part of their regular point of identification and association, and which they can apply without too much economic effort.

Second finding: Sustained collaborative interactions with their stakeholders:

This emphasizes that since organizations are social entities themselves; that is, they cannot isolate themselves from the social context and environment in which they exist and operate, there is the need for consistent interaction between organizations and other social elements in the environment. These interactions must be collaborative and must address ongoing concerns.

Third finding: Must entrench objectivised and externalized processes including policies, methods, etc:

The principle of objectivation and externalization also applies to organizations that are in the process of building a brand. They must cultivate certain cultures, norms, nuances etc, which become a natural and integral way of life for people within the organization. Such an inherent behavioural pattern, consistent across the firm's employees have a strong pull effect on customers, as well as other stakeholders, who value the underlying principles necessitating the behavioural pattern. 
Fourth finding: Sustained interactions with institutions and stakeholders leading to institutionalization

Business organizations interact repeatedly and frequently over time with their stakeholders. These sustained interactions build valuable relationships between business organizations and stakeholders leading to institutionalization. Arguably, the process of branding is situated in the institutionalization process, which is also a signification of interactions and relationships.

Situating the findings of this research into the framework discussed above, it shows that indeed brands are social constructs, which fit into the model of social construction of a brand. The interviews with the brand custodians brought to fore the proposition that brands have a series of nuances, processes and methods that have over time been moulded into habituated patterns for the banks under study; such as the nimble elephant in the logo of First Bank of Nigeria plc, their colours, their payoff, etc. All these have become a cast that they produce without economic efforts. On the other hand, collaboration is premised on interactions with stakeholders. The approach used in this paper identified a host of bank stakeholders (e.g. governments, investing public, financial analysts, customers, staff, etc) were identified, and the methods of interaction were also examined. Objectivation and externalization were situated on the premise that the interviews demonstrated that the banks have objectivated their realities to their staff and to other stakeholders, who over the years, have come to take these two institutions and what they represent as objective realities without questioning.

The index of time must also be factored into the requirements for a successful brand building. As conceptualized in brand construction theory and tested in the interpretive interviews, the two banks under study can be classified as brands that have passed the test/process highlighted in theory. This theory provides a platform whereby brand owners and custodians can situate their efforts to formalize social construction of their brands. Skye Bank plc, though established in 2006 can be said to be a brand. First Bank of Nigeria plc has been in existence for over 117 years.

Recommendations drawn from our empirical findings begin by dissociating the dissonance associated with the brand building process. On the contrary, it is a highly feasible process from the perspective of social construction. Therefore, business organizations seeking to transmute from unbranded companies into developing strong brands can make use of this model to attain their desired objective. In addition, scholars exploring research in brand building processes may consider subjecting our proposed model to further tests. Finally, the scope of social construction methodology for brand building in the literature is still developing, and it is hoped that this methodology as applied in our research will inspire a new generation of researchers on social construction of brand as a methodology in brand research.

\section{References}

Berger, P. L., \& Luckmann, T. (1966). The social construction of reality: a treatise in the sociology of knowledge. London: Penguin Books.

Burmann, C., \& Zeplin, S. (2005). Building brand commitment: a behavioural approach to 
internal brand management. Journal of Brand Management, 279-300. http://dx.doi.org/http://dx.doi.org/10.1057/palgrave.bm.2540223

de Chernatony, L., \& Segal-Horn, S. (2001). Building on services' characteristics to develop successful service brand. Journal of Marketing Management, 17, 645-669. http://dx.doi.org/10.1362/026725701323366773

de Chernatony, L., \& Dall'Olmo Riley, F. (1998b). Defining a "brand": Beyond the literature with experts' interpretations. Journal of Marketing Management, 14, 417-443. http://dx.doi.org/10.1362/026725798784867798

de Chernatony, L., \& Dall'Olmo Riley, F. (1998a). Modelling the components of the brand. European Journal of Marketing, 32(11/12), 1074-1090. http://dx.doi.org/10.1108/03090569810243721

de Chernatony, L., \& Harris, F. (2000). The challenge of financial services branding: majoring on category or brand values. Brand Management \& Marketing Research Unit, 00(6), $1-9$.

Harris, F., \& de Chernatony, L. (2001). Corporate branding and corporate brand performance. European Journal of Marketing, $35(3 \quad$ /4), 441-456. http://dx.doi.org/10.1108/03090560110382101

Karreman, D., \& Rylander, A. (2008). Managing meaning through branding: the case of a consulting firm. Organization Studies, 29(01), 103-125. http://dx.doi.org/10.1177/0170840607084573

Keller, K. (2001). Building customer-based brand equity. Marketing Science Institute, 1-23.

Rust, R. Zeithaml, V., \& Lemon, K. (2004). Customer centered brand management. Harvard Business Review, 1-10.

Shotter, J. (1993). Cultural politics of everyday life: Social constructionism, rhetoric and knowing of the third kind. Buckingham: Open University Press.

Stephen, K. (1991). Brand-building in the 1990s. The Journal of Consumer Marketing, 8(4), 43-52. http://dx.doi.org/10.1108/07363769110035144

Zeman, J. J. (1977). Peirce's theory of signs. A perfusion of signs, 22-39.

\section{Notes}

Note 1. The Central Bank of Nigeria, statutory regulators of Nigeria's financial services sector, announced a reform programme for the nation's banking industry on July 6, 2004. The reform required the existing 89 deposit money banks to raise their capital base to a minimum of N25billion ( $\$ 167$ million) each either through the injection of fresh capital and/or merger and acquisitions. The result saw the emergence of only twenty-five banks at the end of the first phase of the consolidation programme, December 31, 2005.

(Source: http://www.cenbank.org/OUT/SPEECHES/2006/GOVADD\%2016-1-06.PDF) 


\section{Macrothink}

Note 2. The Central Bank of Nigeria (CBN), created by the 1958 Act of Parliament (amended in 2007), possesses overall control and administration of the monetary and financial services sector policies of the Federal Republic of Nigeria (Source: http://www.cbn.gov.ng/).

The Nigeria Deposit Insurance Corporation (NDIC) is an independent agency of the Federal Government of Nigeria set up to protect depositors' funds/investments and guarantee prompt and efficient settlement of insured funds in the event of failure of insured participating institutions (Source: http://www.ndic.org.ng/). 